\title{
Predictive control for hydrogen production by electrolysis in an offshore platform using renewable energies
}

\author{
Álvaro Serna ${ }^{a, b}, *$, Imene Yahyaoui ${ }^{c}$, Julio E. Normey-Rico ${ }^{b}$, \\ César de Prada ${ }^{a}$, Fernando Tadeo ${ }^{a}$ \\ a Dpto de Ingeniería de Sistemas y Automática, Universidad de Valladolid, Valladolid, Spain \\ ${ }^{\mathrm{b}}$ Dpto de Automação e Sistemas, Universidade Federal de Santa Catarina, Florianópolis, Brazil \\ c Dpto de Engenharía Elétrica, Universidade Federal do Espírito Santo, Vitória, Brazil
}

\section{A R T I C L E I N F O}

Article history:

Received 23 May 2016

Received in revised form

2 November 2016

Accepted 10 November 2016

Available online 4 December 2016

Keywords:

Electrolysis

Predictive control

Wave energy

Wind energy

\begin{abstract}
A B S T R A C T
An Energy Management System (EMS), based on Model Predictive Control (MPC) ideas, is proposed here to balance the consumption of power by a set of electrolysis units in an offshore platform. In order to produce renewable hydrogen, the power is locally generated by wind turbines and wave energy converters and fully used by the electrolyzers. The energy generated at the platform by wind and wave is balanced by regulating the operating point of each electrolysis unit and its connections or disconnections, using an MPC based on a Mixed-Integer-Quadratic-Programming algorithm. This Predictive Control algorithm makes it possible to take into account predictions of available power and power consumption, to improve the balance and reduce the number of connections and disconnections of the devices. Two case studies are carried out on different installations composed of wave and wind energies feeding a set of alkaline electrolyzers. Validation using measured data at the target location of the platforms shows the adequate operation of the proposed EMS.
\end{abstract}

(C) 2016 Hydrogen Energy Publications LLC. Published by Elsevier Ltd. All rights reserved.

\section{Introduction}

Hydrogen produced from renewable energies offers significant advantages [1-3]. Some renewable energy sources studied are wind [4-6], waves [7-10], and photovoltaic [11,12]. The usefulness of these energy sources has been verified, the principal problem being their variability [12-15]. In previous works, this problem was solved using hybrid sources (see Refs. [16-18] and references therein). In this paper, we concentrate on offshore co-located wind and wave power sources, as this combination of offshore sources reduces the variability with respect to onshore wind or to wave alone based systems thanks to the low temporal correlation of the resources [19].

Electrolysis is used here to produce $\mathrm{H}_{2}$, as it enables the production of $\mathrm{H}_{2}$ directly from electrical power, and current electrolyzers available in the market can operate intermittently with high efficiency. Many technologies have been proposed, such as polymer electrolysis (PEMEC) [20], alkaline cells and solid oxide electrolysis (SOEC) (see Refs. [2,21,22] and

\footnotetext{
* Corresponding author. Universidad de Valladolid, Departamento de Ingeniería de Sistemas y Automática, C/Doctor Mergelina s/n 47011, Valladolid, Spain.

E-mail addresses: alvaro.serna@autom.uva.es (Á. Serna), imene.yahyaoui@ufes.br (I. Yahyaoui), julio.normey@ufsc.br (J.E. Normey-Rico), prada@autom.uva.es (C. de Prada), fernando@autom.uva.es (F. Tadeo). 
references therein). The class considered in this work are high-pressure and temperature alkaline electrolyzers, as they generate $\mathrm{H}_{2}$ with a purity better than $99.97 \%$, which is the quality used in the automotive industry [23], and are already available at the power levels that make the technology costefficient (about MW; see Refs. [13,24-26] for details). This Energy Management System proposes that the energy consumed is adapted to the available energy by switching on/off electrolysis units and regulating the performance of the devices that are connected, following a smart grid approach for the local micro grid [2]. In comparison with previous works $[2,18,27]$, this proposal focuses on using an advanced control system to optimize $\mathrm{H}_{2}$ production and reduce the connections/disconnections of the appliances [26]. In this work, the produced energy is totally consumed, but the results can be extrapolated to the majority of situations using only the excess energy from green sources [13,29-31]. The proposed EMS is based on Model Predictive Control ideas. Model Predictive Control (MPC) originated in the late seventies and has developed considerably since then. The term MPC does not designate a specific control strategy, but a very ample range of control methods which make an explicit use of a model of the process to obtain the control signal by minimizing an objective function [28].

A previous version of this work was presented in Refs. [18] and [27] within the European project H2Ocean [32] and it is fully developed and improved here. Furthermore, a non-linear model with binary and continuous variables is developed in this paper, which is then transformed in such a way that an MIQP (Mixed-Integer Quadratic Programming) can be used to solve the MPC optimization at each step. Two different case studies are described here to illustrate the performance of the controller.

This work is organized in the following manner: Section materials and methods presents the process description and summarizes the modeling of the components and some MPC ideas. The proposed EMS is presented in Section proposed Energy Management System, fully developing the optimization algorithm. Section case studies presents the two case studies and the validation using measured data from a certain location. Finally, some conclusions are presented at the end of the paper.

\section{Materials and methods}

This work falls within the innovative idea that consists of $\mathrm{H}_{2}$ offshore production by a combination of renewable energies. Besides the models of the plant that were described in Ref. [2], here this paper focuses on the design of an advanced control algorithm of the platform previously considered.

\section{Process description}

Fig. 1 depicts the components of the proposed renewable $\mathrm{H}_{2}$ platform. Two renewable energy sources (wave and wind) supply electricity to the process. This electricity is generated in WECs (Wave Energy Converters) and VAWTs (Vertical Axes Wind Turbines), and is then used in the electrolysis as scheduled by the EMS described in the following sections. An

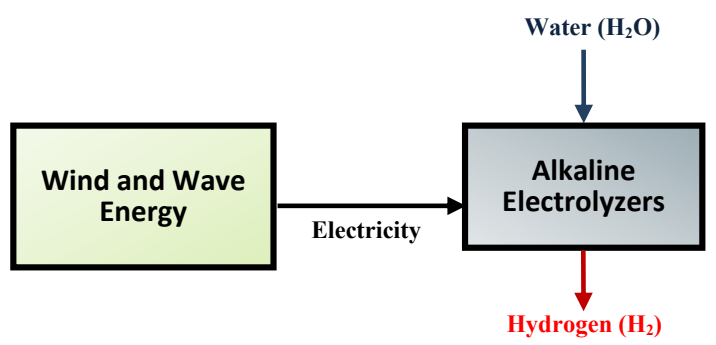

Fig. 1 - Block structure of the renewable hydrogen platform.

electrolyzer is a piece of electrochemical apparatus (something that uses electricity and chemistry at the same time) designed to perform electrolysis: splitting a solution into the atoms from which it is made by passing electricity through it [33]. The proposed EMS is aimed at adapting the production of $\mathrm{H} 2$ to the available energy using degrees of freedom of the advanced control system, so the $\mathrm{H}_{2}$ produced is maximized without degrading the electrolyzers.

\section{Manipulated variables}

The manipulated variables of the proposed EMS are the operating points for each electrolyzer. They are mathematically denoted by $\alpha_{\mathrm{i}}(\mathrm{k})$, where $\mathrm{k}$ represents the discrete time in samples (a sample time of $1 \mathrm{~h}$ is used) and the suffix $\mathrm{i}$ is used to identify each device. Moreover:

a) $\alpha_{\mathrm{i}}(\mathrm{k})=$ 0if the electrolyzer $\mathrm{i}$ is disconnected at time $\mathrm{k}$.

b) $\alpha_{i}(k)$ is between $\left[\begin{array}{ll}\underline{\alpha}_{i} & \bar{\alpha}_{i}\end{array}\right]$ if the electrolyzer is connected, where $\underline{\alpha}_{i}$ and $\bar{\alpha}_{i}$ are minimum and maximum values (between 0 and 1) fixed by the manufacturer due to technological limitations [28]).

In addition, binary variables $\delta_{\mathrm{i}}(\mathrm{k}) \varepsilon\{0,1\}$ are used (see Refs. $[34,35])$, where 0 corresponds to electrolyzer disconnection and 1 to electrolyzer connection.

\section{Model and controlled variables}

The model of the electrolyzers is represented by the following equations with parameters ( $a$ and $b$ ) that are obtained from the manufacturer's data and measurements from the plant:

$\widehat{\mathrm{H}}_{\mathrm{i}}(\mathrm{k})=\frac{\widehat{\alpha}_{\mathrm{i}}(\mathrm{k}) \cdot \widehat{\delta}_{\mathrm{i}}(\mathrm{k})}{\mathrm{a} \cdot \widehat{\alpha}_{\mathrm{i}}(\mathrm{k})+\mathrm{b}}$

$\widehat{\mathrm{P}}_{\mathrm{i}}(\mathrm{k})=\overline{\mathrm{P}}_{\mathrm{i}} \cdot \widehat{\alpha}_{\mathrm{i}}(\mathrm{k}) \cdot \widehat{\delta}_{\mathrm{i}}(\mathrm{k})$

Equations (1) and (2) show the controlled variables of electrolyzer $\mathrm{i}$ : $\widehat{\mathrm{P}}_{\mathrm{i}}(\mathrm{k})$ and $\widehat{\mathrm{H}}_{\mathrm{i}}(\mathrm{k})$. On the one hand, $\widehat{\mathrm{H}}_{\mathrm{i}}(\mathrm{k})$ is the predicted $\mathrm{H}_{2}$ production of electrolyzer $\mathrm{i}$ at time $\mathrm{k}$. On the other hand, $\widehat{\mathrm{P}}_{\mathrm{i}}(\mathrm{k})$ is the predicted energy consumption of device $i$ and $\bar{P}_{i}$ is its maximum power at the same sample time. Parameters $a_{i}, b_{i}$ and $\bar{P}_{i}$ are used to define the device performance. This performance is called the relationship between consumed energy and $\mathrm{H}_{2}$ production. Note that the model of the electrolyzers is static because the time required for them 
to vary $\alpha$ from the minimum to the maximum value is less than a few minutes in the worst case, thus, these dynamics can be neglected as the sampling time for the EMS proposed here is one hour. Fig. 2 shows the ratio $\mathrm{H}_{\mathrm{i}} / \mathrm{P}_{\mathrm{i}}$ in the production of $\mathrm{H}_{2}$ by electrolysis as a function of the operating point $(\alpha)$ for the different types of electrolyzers, which will be explained in the two case studies of Section case studies.

\section{Model Predictive Control}

Comparing with other methods of process control, MPC can be used to solve the most common problems in today's industrial processes, which need to be operated under tight performance specifications where many constraints need to be satisfied [36]. The principal elements in MPC are the objective function to be minimized, the model used to compute the predictions of the controlled variables, the definition of the process constraints and the method applied to solve the optimization problem [28]. Fig. 3 depicts the MPC scheme; where the optimization block receives information from the model block, which is responsible for computing the predictions of the plant output in a defined horizon. A model is used to predict the future outputs, based on past and current values and on the proposed optimal future control actions. These actions are calculated by the optimizer taking into account the cost function (where the future tracking error is considered) as well as the constraints [28].

\section{Proposed Energy Management System}

In Section introduction, the fact that alkaline electrolyzers have been selected to operate in the offshore platform was mentioned. A set of alkaline electrolyzers that might have different characteristics are assumed in this work, to reproduce installations that might have different electrolyzers, or

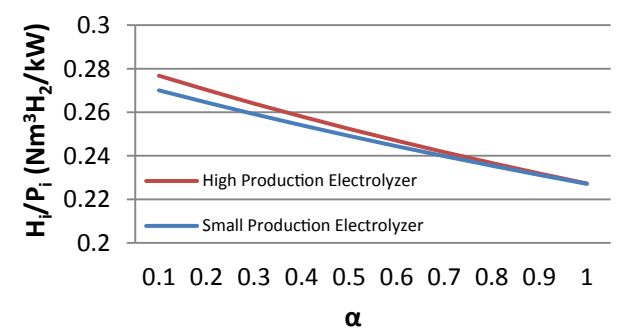

Fig. 2 - Hydrogen production of the electrolyzers.

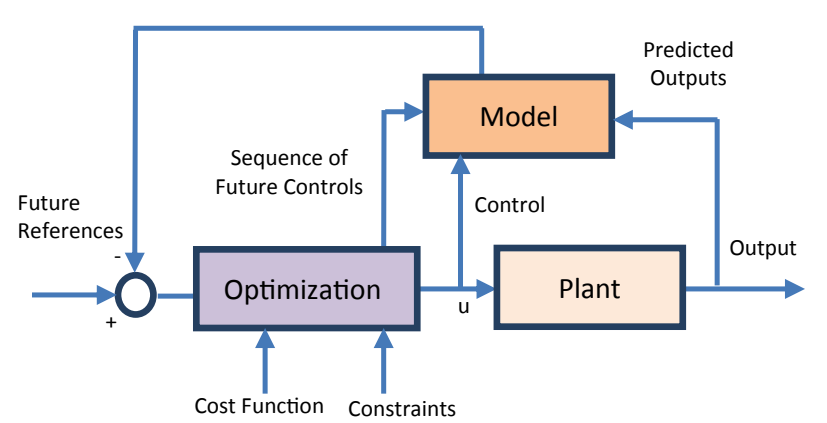

Fig. 3 - Model Predictive Control scheme. electrolyzers with changing parameters due to aging, maintenance, etc, $\mathrm{n}$ being the number of devices.

\section{Control objectives}

The control algorithm designed in this work aims to maximize the $\mathrm{H}_{2}$ produced by electrolysis considering different aspects, such as the limitation in the available power and the operational constraints. Three main objectives must be fulfilled:

Objective 1: To maximize the $\mathrm{H}_{2}$ production, the difference between the values of the prediction and its desired values for each electrolyzer is minimized for all the devices along the prediction horizon $(\mathrm{N})$.

Objective 2: To maximize the operation of the devices, the discrete variables defining the connection/disconnection condition should be, whenever possible, equal to one (connection condition) along $\mathrm{N}$.

Objective 3: Energy consumed by the devices should always be smaller than the energy supplied from the wind and waves but will try to be equal.

\section{Cost function and optimization problem}

Equation (3) shows the quadratic cost function considered in this work, which is minimized at each sample time to find the optimal control action.

$$
\begin{gathered}
J=\sum_{i=1}^{n} \sum_{j=1}^{N}\left[\left(\widehat{H}_{i}(k+j)-\bar{H}_{i}(k+j)\right)^{2} Q_{H i}+\sum_{i=1}^{n}\right. \\
\left.\times \sum_{j=1}^{N_{u}}\left(\widehat{\delta}_{i}(k+j)-1\right)^{2} Q_{\delta i}\right]
\end{gathered}
$$

This equation considers, in prediction and control horizons of $\mathrm{N}$ and $\mathrm{N}_{\mathrm{u}}$ samples respectively, the error between the predictions of $\mathrm{H}_{2}$ produced $\left(\widehat{\mathrm{H}}_{\mathrm{i}}\right)$ and the desired values $\left(\overline{\mathrm{H}}_{\mathrm{i}}\right)$, while also penalizing the number of connections and disconnections. Besides, $\mathrm{Q}_{\mathrm{HI}}$ and $\mathrm{Q}_{\delta \mathrm{i}}$ are the weighting factors for the error and the control action, respectively. The first term of (3) is used for Objective 1, while the second term of this equation tries to achieve Objective 2 of Section control objectives. To solve this problem, the future predictions of the $\mathrm{H}_{2}$ production are expressed as a function of the future control actions and the past values of the input and outputs using the electrolyzer models (1) and (2). Thus, using equation (3) with all the system constraints and the electrolyzer models, it can be shown that the optimization problem to be solved at each sample time is (4).

$\min _{\left(\alpha_{\mathrm{i}}, \delta_{\mathrm{i}}\right)} \mathrm{J}$

$$
\begin{aligned}
& \text { s.t. } \quad \delta \in[0,1] \\
& \alpha_{i_{i}} \leq \alpha_{i} \leq \bar{\alpha}_{i} \\
& \widehat{\mathrm{P}}_{\mathrm{i}}(\mathrm{k})=\overline{\mathrm{P}}_{\mathrm{i}} \cdot \widehat{\alpha}_{\mathrm{i}}(\mathrm{k}) \cdot \widehat{\delta}_{\mathrm{i}}(\mathrm{k}) \\
& \widehat{\mathrm{H}}_{\mathrm{i}}(\mathrm{k})=\frac{\widehat{\alpha}_{\mathrm{i}}(\mathrm{k}) \cdot \widehat{\delta}_{\mathrm{i}}(\mathrm{k})}{\mathrm{a} \cdot \widehat{\alpha}_{\mathrm{i}}(\mathrm{k})+\mathrm{b}} \\
& \sum_{\mathrm{i}=1}^{\mathrm{n}} \widehat{\mathrm{P}}_{\mathrm{i}}(\mathrm{k}) \leq \widehat{\mathrm{P}}_{\text {available }}(\mathrm{k})
\end{aligned}
$$


Because of the non-linear model of the electrolyzer (see equation (1)) and the use of discrete $(\delta)$ and real $(\alpha)$ decision variables, the problem to be solved by the MPC control algorithm is, at each $\mathrm{k}$, an NLMIQP (Non-Linear Mixed Integer Quadratic Problem) that is very complicated to solve. Hence, a simple solution will be proposed in the next section.

\section{Approximation to an MIQP}

The main goal of this paper is to transform problem (4) into a Mixed-Integer Quadratic Problem with linear constraints (MIQP). To do so, each electrolyzer model is first modified using the following change of variable:

$\mathrm{z}_{\mathrm{i}}(\mathrm{k})=\alpha_{\mathrm{i}}(\mathrm{k}) \cdot \delta_{\mathrm{i}}(\mathrm{k})$

where $z_{i}$ is now a real variable: $z_{i} \in \mathbb{R}$. The model of the $\mathrm{H}_{2}$ production is now given by:

$\widehat{\mathrm{H}}_{\mathrm{i}}(\mathrm{k})=\frac{\widehat{\mathrm{z}}_{\mathrm{i}}(\mathrm{k})}{\mathrm{a} \cdot \widehat{\alpha}_{\mathrm{i}}(\mathrm{k})+\mathrm{b}}$

$\widehat{\mathrm{P}}_{\mathrm{i}}(\mathrm{k})=\overline{\mathrm{P}}_{\mathrm{i}} \cdot \widehat{\mathrm{Z}}_{\mathrm{i}}(\mathrm{k})$

Note that the predictions of the $\mathrm{H}_{2}$ produced do not depend on past values because a static model for the electrolyzers was considered. It can be seen in equation (6) that $\mathrm{H}_{\mathrm{i}}=0$ and $\mathrm{z}_{\mathrm{i}}=0$ if $\delta_{i}=0$ while $z_{i}=\alpha_{i}$ if $\delta_{i}=1$. Therefore equation (8) can be rewritten to eliminate the dependence between $\alpha_{\mathrm{i}}$ and $\mathrm{H}_{\mathrm{i}}$ :

$\widehat{\mathrm{H}}_{\mathrm{i}}(\mathrm{k})=\frac{\widehat{\mathrm{z}}_{\mathrm{i}}(\mathrm{k})}{\mathrm{a} \cdot \widehat{\mathrm{z}}_{\mathrm{i}}(\mathrm{k})+\mathrm{b}}$

Thereby, $\mathrm{H}_{\mathrm{i}}$ is now a real function of the real variable $\mathrm{z}_{\mathrm{i}}$. As $z_{i}$ is in the $[0,1]$ interval, $a>0$ and $b>0, H_{i}\left(z_{i}\right)$ is differentiable and continuous in the interval $[0,1]$. In equation $(8) \mathrm{H}_{\mathrm{i}}\left(\mathrm{z}_{\mathrm{i}}\right)$ is a nonlinear function, so the relationship between $\widehat{z}(k+j)$ and $\widehat{\mathrm{H}}(\mathrm{k}+\mathrm{j})$ will not be linear either. It is necessary to make another approximation in the predictions to modify the optimization problem into an MIQP which is less difficult to solve. To linearize future predictions of the $\mathrm{H}_{2}$ production, an approximation using a first order truncation Taylor series can be done:

$\mathrm{H}_{\mathrm{i}}\left(\mathrm{z}_{\mathrm{i}}+\Delta \mathrm{z}_{\mathrm{i}}\right)=\mathrm{H}_{\mathrm{i}}\left(\mathrm{z}_{\mathrm{i}}\right)+\frac{\partial \mathrm{H}_{\mathrm{i}}}{\partial \mathrm{z}_{\mathrm{i}}}\left(\mathrm{z}_{\mathrm{i}}\right) \Delta \mathrm{z}_{\mathrm{i}}$

Hence, simplifying the notation, and enforcing the same method for the $\mathrm{N}$ predictions of the $\mathrm{H}_{2}$ production, gives:

$$
\begin{aligned}
& \widehat{\mathrm{H}_{1}}(\mathrm{k}+1)=\mathrm{H}_{\mathrm{i}}(\mathrm{k})+\frac{\mathrm{b}_{\mathrm{i}}}{\left(\mathrm{a}_{\mathrm{i}} \mathrm{z}_{\mathrm{i}}(\mathrm{k})+\mathrm{b}_{\mathrm{i}}\right)^{2}} \cdot \widehat{\Delta \mathrm{z}_{1}}(\mathrm{k}+1) \\
& \widehat{\mathrm{H}_{1}}(\mathrm{k}+2)=\mathrm{H}_{\mathrm{i}}(\mathrm{k})+\frac{\mathrm{b}_{\mathrm{i}}}{\left(\mathrm{a}_{\mathrm{i}} \cdot \mathrm{z}_{\mathrm{i}}(\mathrm{k})+\mathrm{b}_{\mathrm{i}}\right)^{2}} \cdot\left(\widehat{\Delta \mathrm{z}_{1}}(\mathrm{k}+1)+\widehat{\Delta \mathrm{z}_{1}}(\mathrm{k}+2)\right) \\
& \begin{array}{lll}
\ldots & \ldots & \ldots
\end{array} \\
& \widehat{\mathrm{H}_{\mathrm{l}}}(\mathrm{k}+\mathrm{N})=\mathrm{H}_{\mathrm{i}}(\mathrm{k})+\frac{\mathrm{b}_{\mathrm{i}}}{\left(\mathrm{a}_{\mathrm{i}} \cdot \mathrm{z}_{\mathrm{i}}(\mathrm{k})+\mathrm{b}_{\mathrm{i}}\right)^{2}} \cdot\left(\widehat{\Delta \mathrm{Z}_{1}}(\mathrm{k}+1)+{\widehat{\Delta \mathrm{z}_{1}}}_{\mathrm{L}}(\mathrm{k}+2)+\right. \\
& \cdots \widehat{\Delta z}_{1}(\mathrm{k}+\mathrm{Nu})
\end{aligned}
$$

Defining $g_{i}=\frac{b_{i}}{\left(a_{i} \cdot z_{i}(k)+b_{i}\right)^{2}}$, vector $1=\left[\begin{array}{llll}1 & 1 & \ldots & 1\end{array}\right]^{\mathrm{T}}$ (dimension $1 \times \mathrm{N}$ ) and $\mathrm{T}$ has dimension $\mathrm{N} \times \mathrm{N}_{\mathrm{u}}$.
$\operatorname{Matrix~T}=\overbrace{\left[\begin{array}{cccc}1 & 0 & \cdots & \cdots \\ 1 & 1 & 0 & \cdots \\ 1 & 1 & 1 & 0 \\ 1 & 1 & 1 & 1 \\ 1 & 1 & 1 & 1\end{array}\right]}^{N_{u}} N$

Predictions are given by the following vector for each $\mathrm{i}$ :

$\widehat{\mathrm{H}_{\mathrm{i}}}=\left[\widehat{\mathrm{H}_{\mathrm{i}}}(\mathrm{k}+1) \ldots . \widehat{\mathrm{H}_{\mathrm{i}}}(\mathrm{k}+\mathrm{N})\right]^{\mathrm{T}}$

$\widehat{\mathrm{H}}_{\mathrm{i}}=1 \cdot \mathrm{H}_{\mathrm{i}}(\mathrm{k})+\mathrm{g}_{\mathrm{i}} \cdot \mathrm{T} \cdot \widehat{\Delta \mathbf{z}_{\mathrm{i}}}$

where:

$\widehat{\Delta \mathbf{z}_{\mathrm{i}}}=\left[\widehat{\Delta \mathbf{z}_{\mathrm{i}}}(\mathrm{k}+1) \ldots . \widehat{\Delta \mathrm{z}_{\mathrm{i}}}(\mathrm{k}+\mathrm{Nu})\right]^{\mathrm{T}}$

The manipulated variables are $\Delta \mathrm{z}_{\mathrm{i}}(\mathrm{k}), \alpha_{\mathrm{i}}(\mathrm{k})$ and $\delta_{\mathrm{i}}(\mathrm{k})$. Hence, the relationship between the manipulated variables and the predictions can be rewritten by calculating the future control movements in the following vector:

$\Delta \mathbf{u}_{\mathrm{i}}=\left[\begin{array}{c}\Delta \mathrm{z}_{\mathrm{i}}(\mathrm{k}+1) \\ \Delta \mathrm{z}_{\mathrm{i}}(\mathrm{k}+2) \\ \cdots \\ \Delta \mathrm{z}_{\mathrm{i}}(\mathrm{k}+\mathrm{Nu}) \\ \alpha_{\mathrm{i}}(\mathrm{k}+1) \\ \alpha_{\mathrm{i}}(\mathrm{k}+1) \\ \cdots \\ \alpha_{\mathrm{i}}(\mathrm{k}+\mathrm{Nu}) \\ \delta_{\mathrm{i}}(\mathrm{k}+1) \\ \delta_{\mathrm{i}}(\mathrm{k}+2) \\ \cdots \\ \delta_{\mathrm{i}}(\mathrm{k}+\mathrm{Nu})\end{array}\right]=\left[\begin{array}{c}\Delta \mathbf{z}_{\mathrm{i}} \\ \\ \boldsymbol{\alpha}_{\mathrm{i}} \\ \\ \delta_{\mathrm{i}}\end{array}\right]$

which has dimension $3 \mathrm{~N}_{\mathrm{u}} \times 1$; the matrix $\mathrm{G}_{\mathrm{i}}$ :

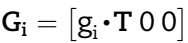

which has dimension $\mathrm{N} \times 3 \mathrm{~N}_{\mathrm{u}}$, thus:

$\mathrm{H}_{\mathrm{i}}=\mathrm{f}_{\mathrm{i}}+\mathrm{G}_{\mathrm{i}} \cdot \Delta \mathrm{u}_{\mathrm{i}}$

Equation (17) describes the $\mathrm{H}_{2}$ produced by a certain device, where $f_{i}$ is the free response computed using the nonlinear model written in (8) for $\mathrm{H}_{\mathrm{i}}(\mathrm{k})$ and $\mathrm{G}_{\mathrm{i}}$. Also, $\Delta \mathbf{u}_{\mathrm{i}}$ is the linearized forced response $[28,37]$. Now, taking into account the set of $n$ devices:

$\mathrm{H}=\left[\mathrm{H}_{1} \mathrm{H}_{2} \ldots \mathrm{H}_{\mathbf{n}}\right]^{\mathrm{T}}$

$\mathbf{f}=\left[\mathbf{f}_{1} \mathbf{f}_{2} \ldots \mathbf{f}_{\mathbf{n}}\right]^{\mathrm{T}}$

$\Delta \mathrm{U}=\left[\Delta \mathrm{U}_{1} \Delta \mathrm{U}_{2} \ldots \Delta \mathrm{U}_{\mathrm{n}}\right]^{\mathrm{T}}$

where $\mathrm{H}$ and $\mathrm{f}$ are $\mathrm{N} \cdot \mathrm{n} \times 1$ vectors and $\Delta \mathrm{U}$ is an $\mathrm{N}_{\mathrm{u}} \cdot \mathrm{n} \times 1$ vector, it follows that:

$\mathrm{H}=\mathrm{f}+\mathrm{G} \cdot \Delta \mathrm{U}$ 
where:

$\mathbf{G}=\left[\begin{array}{cccc}\mathrm{G}_{1} & 0 & 0 & 0 \\ 0 & \mathrm{G}_{2} & 0 & 0 \\ 0 & 0 & \cdots & 0 \\ 0 & 0 & 0 & \mathrm{G}_{\mathrm{n}}\end{array}\right]$

Equation (21) relates, in a linear manner, the manipulated variables (vector $\Delta \mathrm{U}$ ) and the controlled variables (vector $\mathrm{H}$ ), thus the nonlinear problems in (4) are eliminated.

\section{Constraints}

In Section approximation to an MIQP, a new decision variable $\mathrm{z}$ was defined to simplify the optimization problem that had to be solved as part of the Predictive Control strategy. Here, the constraints in (4) are modified into an MLD (Mixed Logical Dynamical System, $[38,39])$ to associate the performance of the platform with the discrete variable $\delta$ and the continuous variable $\alpha$, and to linearize the model. Thus, constraints (23)-(28) show this idea for all the cases where the binary variable could be 0 or 1 and $j=1 \ldots N$.

$\mathrm{z}_{\mathrm{i}}(\mathrm{k})+\sum_{\mathrm{l}=1}^{\mathrm{j}} \Delta \mathrm{z}_{\mathrm{i}}(\mathrm{k}+\mathrm{l}) \leq \bar{\alpha}_{\mathrm{i}} \cdot \delta_{\mathrm{i}}(\mathrm{k}+\mathrm{j})$

$\mathrm{z}_{\mathrm{i}}(\mathrm{k})+\sum_{\mathrm{l}=1}^{\mathrm{j}} \Delta \mathrm{z}_{\mathrm{i}}(\mathrm{k}+\mathrm{l}) \geq \underline{\alpha}_{\mathrm{i}} \cdot \delta_{\mathrm{i}}(\mathrm{k}+\mathrm{j})$

$\mathrm{z}_{\mathrm{i}}(\mathrm{k})+\sum_{\mathrm{l}=1}^{\mathrm{j}} \Delta \mathrm{z}_{\mathrm{i}}(\mathrm{k}+\mathrm{l}) \leq \alpha_{\mathrm{i}}(\mathrm{k}+\mathrm{l})-\underline{\alpha}_{\mathrm{i}}\left(1-\delta_{\mathrm{i}}(\mathrm{k}+\mathrm{j})\right)$

$\mathrm{z}_{\mathrm{i}}(\mathrm{k})+\sum_{\mathrm{l}=1}^{\mathrm{j}} \Delta \mathrm{z}_{\mathrm{i}}(\mathrm{k}+\mathrm{l}) \geq \alpha_{\mathrm{i}}(\mathrm{k}+\mathrm{l})-\bar{\alpha}_{\mathrm{i}}\left(1-\delta_{\mathrm{i}}(\mathrm{k}+\mathrm{j})\right)$

$\alpha_{i}(k+j) \leq \bar{\alpha}_{i}$

$\alpha_{\mathrm{i}}(\mathrm{k}+\mathrm{j}) \geq \underline{\alpha}_{\mathrm{i}}$

Besides constraints (23)-(28), the following constraint (29) must be considered to fulfill Objective 3: At each sample (k), the total energy consumed should always be smaller than the predicted energy available from the wind and waves $\left(\widehat{\mathrm{P}}_{\text {available }}(\mathrm{k})\right)$. Considering MPC ideas, the vector of predictions of available power, $\widehat{\mathrm{P}}_{\text {available }}(\mathrm{k})$, is calculated over $\mathrm{N}$ using real meteorological data. Hence, the constraint in the consumed energy is:

$\sum_{\mathrm{i}=1}^{\mathrm{n}} \overline{\mathrm{P}}_{\mathrm{i}} \cdot \widehat{\mathrm{z}}_{\mathrm{i}}(\mathrm{k}+\mathrm{j}) \leq \widehat{\mathrm{P}}_{\text {available }}(\mathrm{k}+\mathrm{j}) \quad \mathrm{j}=1,2, \ldots, \mathrm{N}$

Thus, the constraints defined in equations (23)-(29) are linear in the decision variables $\Delta z, \alpha$ and $\delta$, so the optimization problem can be solved using Mixed-Integer Quadratic Programming (MIQP).

\section{Optimization}

To summarize, the MPC problem of minimizing the cost function (4) subject to (23)-(29) can be transformed into the following MIQP: $\min _{\Delta \mathrm{U}} \frac{1}{2} \Delta \mathrm{U}^{\mathrm{T}} \cdot \mathrm{M} \cdot \Delta \mathrm{U}+\mathrm{l}^{\mathrm{T}} \cdot \Delta \mathrm{U}$
s.t. $\mathrm{A} \cdot \Delta \mathrm{U}<\mathrm{B}$

Equation (30) can be solved at each sample time. Matrices A and $\mathbf{B}$ define the constraints of the problem. Equation (31) can be obtained using equation (21) in the cost function:

$$
\mathbf{J}=\left[(\mathbf{f}+\mathbf{G} \Delta \mathbf{U}-\overline{\mathbf{H}})^{\mathrm{T}} \mathbf{Q}_{\mathrm{H}}(\widehat{\mathbf{f}}+\mathbf{G} \Delta \mathbf{U}-\overline{\mathrm{H}})+(\widehat{\boldsymbol{\delta}}-1)^{\mathrm{T}} \mathrm{Q}_{\boldsymbol{\delta}}(\widehat{\boldsymbol{\delta}}-1)\right]
$$

Taking into account the relationship between $\widehat{\delta}$ and $\Delta U$, equation (31) can be manipulated to give the cost function to be solved:

$\mathrm{J}:=\frac{1}{2} \Delta \mathrm{U}^{\mathrm{T}} \cdot \mathrm{M} \cdot \Delta \mathrm{U}+\mathrm{l}^{\mathrm{T}} \cdot \Delta \mathrm{U}$

Matrices $\mathbf{l}$ and $\mathbf{M}$ are the linear and quadratic part of the quadratic optimization problem, respectively. They are given by equations (33) and (34):

$l=2 \mathrm{f}^{\mathrm{T}} \mathrm{Q}_{\mathrm{H}} \mathrm{G}-2 \overline{\mathrm{H}}^{\mathrm{T}} \mathrm{Q}_{\mathrm{H}} \mathrm{G}$

$\mathrm{M}=\mathrm{G}^{\mathrm{T}} \mathrm{Q}_{\mathrm{H}} \mathrm{G}$

All the constraints (23)-(29) can be rewritten in the compact form $\mathbf{A} \cdot \Delta \mathbf{U} \leq \mathbf{B}$. The dimensions of matrices $\mathbf{l}, \mathbf{M}, \mathbf{A}$ and $\mathbf{B}$ depend on the number of electrolyzers (n) and the control horizon $\mathrm{N}_{\mathrm{u}}$. These matrices have the following dimensions: $\mathbf{M} \in \mathbb{R}^{(3 \mathrm{nNu} \times 3 \mathrm{nNu})}, \quad \mathbf{l} \in \mathbb{R}^{3 \mathrm{nNu}}, \quad \mathbf{B} \in \mathbb{R}^{(6 \mathrm{nNu}+\mathrm{Nu})}$ and $\mathrm{A} \in \mathbb{R}^{((6 \mathrm{nNu}+\mathrm{Nu}) \times 3 \mathrm{nNu})}$.

\section{Case studies}

As detailed in Section process description, the platform is made up of two different parts: one is the energy source and the other consumes the energy to generate $\mathrm{H}_{2}$.

To produce the energy for the renewable $\mathrm{H}_{2}$ plant, two sources (wind and wave) have been considered in both case studies. Wind energy was chosen as it is a mature technology [40] and wave energy as it provides lower variability in the energy production [41]. A co-located hybrid device of 1 vertical axis wind turbine (VAWT) of 5.0 MW peak power and 1 wave energy converter (WEC) of 1.6 MW peak power were chosen, according to the studies developed in the project H2Ocean [32]. This hybrid VAWTWEC device (shown in Fig. 4) is assumed to provide the energy: it consists of a platform with a hull (where the VAWT is located) and a cross bridge where four pitching wave energy converters are placed. The wave energy converters also reduce the motion of the platform and passively rotate it to face the waves.

To produce $\mathrm{H}_{2}$, different NEL A485 electrolyzers (NELHydrogen, 2014) were chosen. The main gas storage containers are located on two other floating units, well separated from both the $\mathrm{H}_{2}$ production and each other. The alkaline electrolyzers operate slightly above ambient pressure and are further equipped with pressure relief equipment, to prevent overpressure operation. 


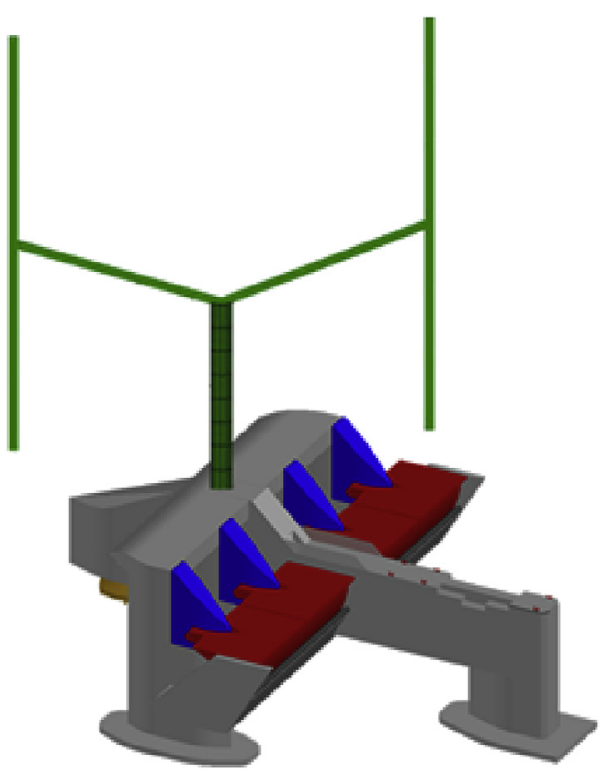

Fig. 4 - A co-located hybrid VAWT-WEC device [42].

\section{First case study}

A simulation was carried out using one hybrid device of 6.6 MW $(5.0+1.6)$ for the energy production. Three electrolyzers (two high production of 2.134 MW rated and one small production of $0.220 \mathrm{MW}$ rated) were chosen for this first case study. The sections below detail the controller implementation and a discussion of the results.

Controller implementation

A control horizon of $3 \mathrm{~h}$ and a prediction horizon of $3 \mathrm{~h}$ were selected. Thus, $\mathrm{n}=3, \mathrm{~N}_{\mathrm{u}}=3$ and $\mathrm{N}=3$. These are the parameters of the plant analyzed in this case study:

$$
\begin{aligned}
& \overline{\mathrm{P}}=\left[\begin{array}{lll}
2134 & 2134 & 220
\end{array}\right]^{\mathrm{T}} \\
& \overline{\mathrm{a}}=\left[\begin{array}{lll}
0.875 & 0.875 & 0.778
\end{array}\right]^{\mathrm{T}} \\
& \overline{\mathrm{b}}=\left[\begin{array}{lll}
3.525 & 3.525 & 3.625
\end{array}\right]^{\mathrm{T}} \\
& \overline{\mathrm{H}}=\left[\begin{array}{lll}
485 & 485 & 485
\end{array}\right]^{\mathrm{T}} \\
& \bar{\alpha}=\left[\begin{array}{lll}
1 & 1 & 1
\end{array}\right]^{\mathrm{T}} \\
& \underline{\alpha}=\left[\begin{array}{lll}
0.2 & 0.2 & 0.1
\end{array}\right]^{\mathrm{T}} \\
& \mathrm{Q}_{\mathrm{H}}=\left[\begin{array}{lll}
1 & 1 & 50
\end{array}\right]^{\mathrm{T}} \\
& \mathrm{Q}_{\delta}=\left[\begin{array}{lll}
1 & 1 & 1
\end{array}\right]^{\mathrm{T}}
\end{aligned}
$$

To optimize this problem, an MIQP solver in the Matlab ${ }$ CPLEX was used to solve (30). A sampling time of $1 \mathrm{~h}$ was chosen to validate the EMS. In the two proposals analyzed here, the current available energy at each time $\mathrm{k}$ is different from the one predicted in the previous step. Bounds $\left[\underline{\alpha}_{i}\right.$ and $\bar{\alpha}_{\mathrm{i}}$ were selected using data from the electrolyzer manufacturers.
Results and discussion

For this first case study, some results for $140 \mathrm{~h}$ of operation are shown in Figs. 5-9. These results confirm the correct operation of the advanced control system designed in this paper for the parameters considered. Fig. 5 shows the power provided by the renewable energy sources (black line) and the power consumed (red line) by the electrolyzers. As can be seen in the simulations, the controller tries to maintain the consumed power very near the available one. As a consequence of this, the $\mathrm{H}_{2}$ produced is near the achievable maximum. This happens because in this first case study the parameters chosen for the electrolyzers suppose an ideal performance.

Fig. 6 shows the performance of the electrolyzer $i=1$ (high production). As expected, this device is not connected/ disconnected very often and $\alpha$ is always between $\bar{\alpha}$ and $\underline{\alpha}$. On the other hand, Fig. 7 shows the performance of the second high production electrolyzer $(\mathrm{i}=2)$. This performance is different from the one before because here the operating point is almost always in the same value, which is the lower bound. As it is not disconnected frequently, it can be considered that the control algorithm is well designed and tuned.

Electrolyzer $\mathrm{i}=3$ (Fig. 8) is more connected because its performance is bigger than the performance of the high production electrolyzers, therefore the operation of this device can also be considered correct. In all cases, the values of the computed manipulated variables are between the defined bounds. The last figure of this case study depicts the $\mathrm{H}_{2}$ produced by the three devices. As expected, it proportionally depends on the power consumed, as shown in Fig. 5.

\section{Second case study}

A different simulation was carried out using three hybrid devices of 6.6 MW each (total of 19.8 MW) for the energy production. Six electrolyzers (three high and three small production) were chosen for this second case study. The sections below detail the controller implementation and a discussion of the results.

\section{Controller implementation}

This second proposal is more realistic in comparison with the previous one. The rated power of the electrolyzers is not the maximum value, but a loss-of-performance factor was added for each device. These are the parameters of the platform in this second case study:

$$
\begin{aligned}
& \overline{\mathrm{P}}=\left[\begin{array}{llllll}
2066.7 & 2025.6 & 2014.6 & 201.2 & 208.5 & 200.6
\end{array}\right]^{\mathrm{T}} \\
& \overline{\mathrm{a}}=\left[\begin{array}{lllllll}
0.8706 & 0.8697 & 0.8670 & 0.8089 & 0.7882 & 0.7731
\end{array}\right]^{\mathrm{T}} \\
& \overline{\mathrm{b}}=\left[\begin{array}{llllll}
3.5271 & 3.5301 & 3.6124 & 3.6809 & 3.6406 & 3.5101
\end{array}\right]^{\mathrm{T}} \\
& \overline{\mathrm{H}}=\left[\begin{array}{llllll}
485 & 485 & 485 & 485 & 485 & 485
\end{array}\right]^{\mathrm{T}} \\
& \bar{\alpha}=\left[\begin{array}{lllllll}
1 & 1 & 1 & 1 & 1 & 1
\end{array}\right]^{\mathrm{T}} \\
& \underline{\alpha}=\left[\begin{array}{llllll}
0.2 & 0.2 & 0.2 & 0.1 & 0.1 & 0.1
\end{array}\right]^{\mathrm{T}}
\end{aligned}
$$




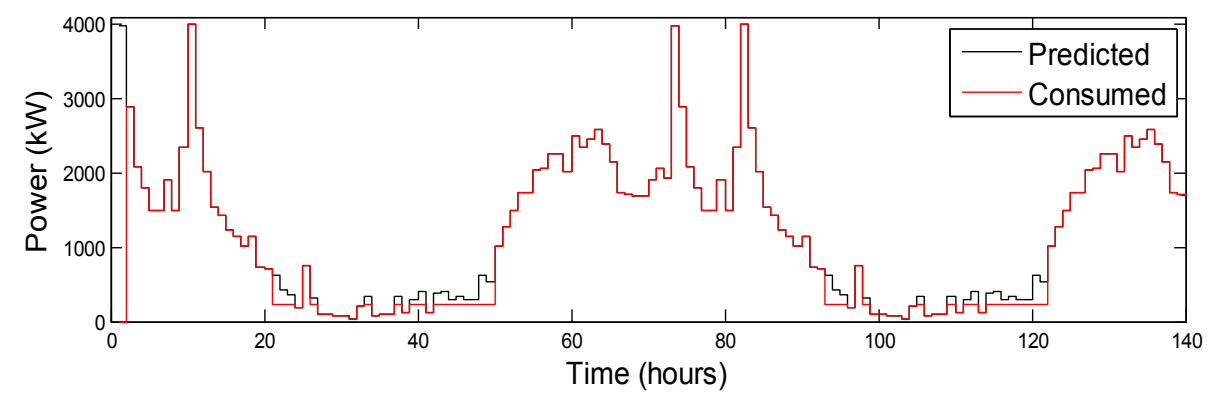

Fig. 5 - Power available and consumed first case study.

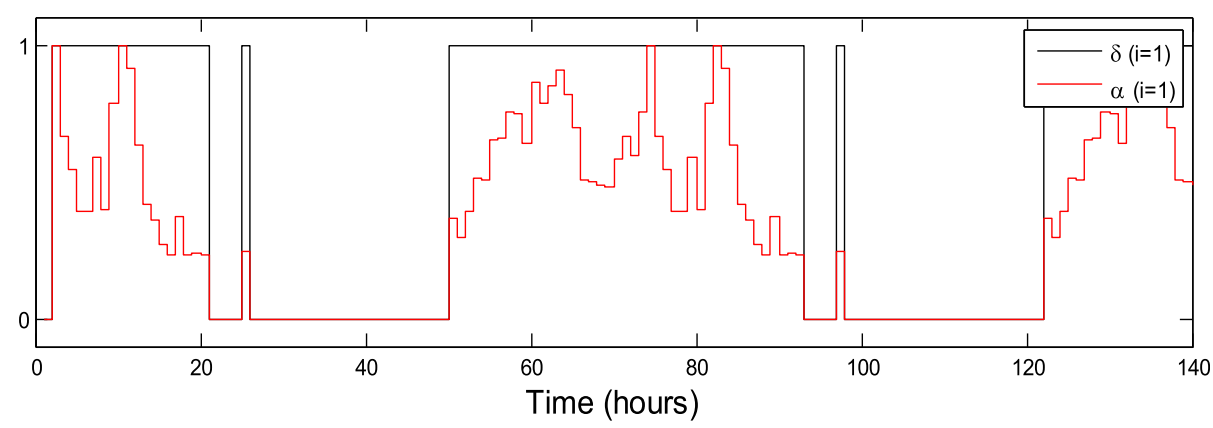

Fig. 6 - Performance of electrolyzer number 1 for the first case study.

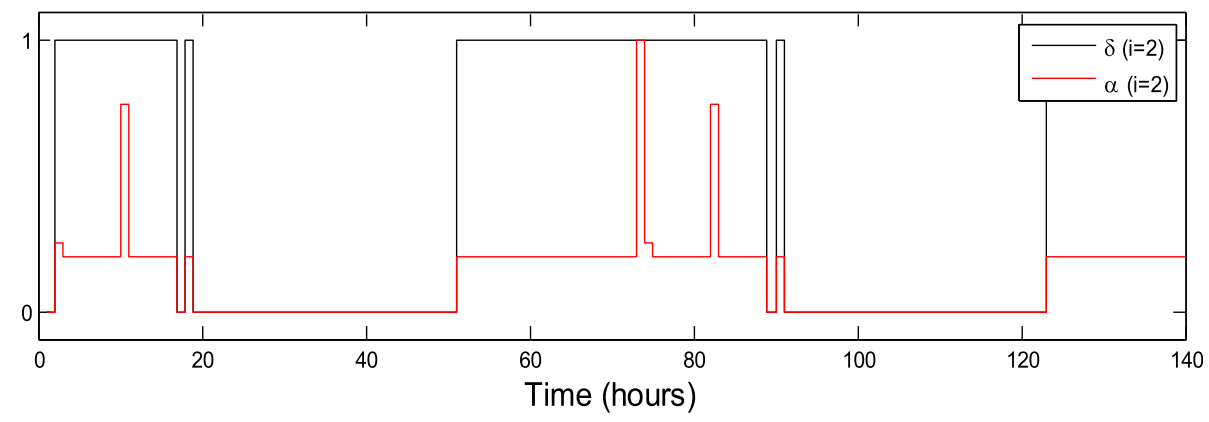

Fig. 7 - Performance of electrolyzer number 2 for the first case study.

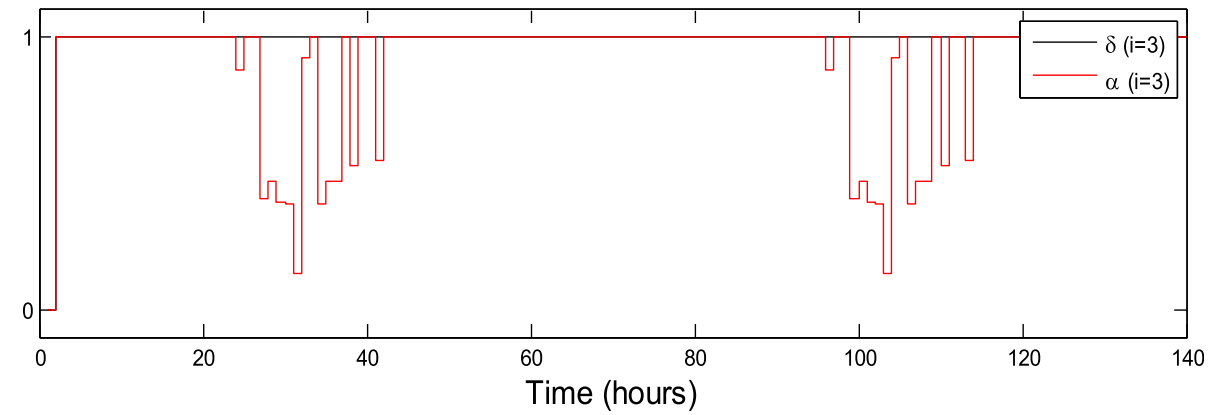

Fig. 8 - Performance of electrolyzer number 3 for the first case study. 


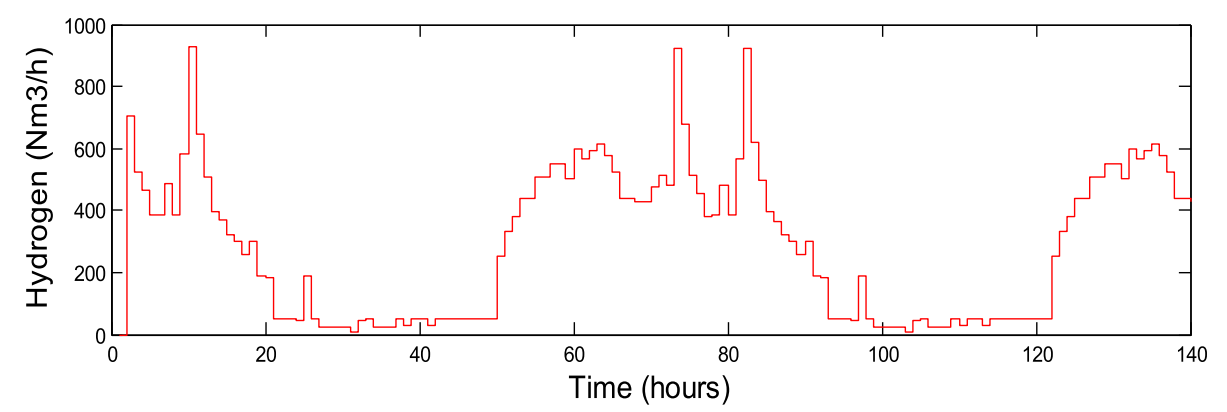

Fig. 9 - Hydrogen production for the first case study.

$Q_{H}=\left[\begin{array}{llllll}1 & 1 & 1 & 500 & 500 & 500\end{array}\right]^{\mathrm{T}}$

$\mathrm{Q}_{\delta}=\left[\begin{array}{llllll}100 & 1000 & 10000 & 300 & 400 & 200\end{array}\right]^{\mathrm{T}}$

The same optimization toolbox was used to carry out the simulation and optimization. A simulation has been done with a prediction and control horizon of $3 \mathrm{~h}(\mathrm{n}=6, \mathrm{~N}=3$ and $\mathrm{Nu}=3$ ) and taking a sample time of $1 \mathrm{~h}$.

\section{Results and discussion}

For the second case study, some results for $140 \mathrm{~h}$ of operation are shown in Figs. 10-17. The results confirm the correct operation of the advanced control system for this case. Fig. 10 shows the power available for the electrolysis. Effectively, the available power is always slightly bigger than the power consumed by the electrolyzers. Unlike the previous case study, where the available power was almost equal to the consumed power, in this second case study the difference is bigger because the electrolyzer parameters are not ideal.

Figs. 11-13 show the performance of the three high production electrolyzers. As expected, they are not switched on/ off very frequently. In comparison with the previous case study, it can be seen that the power was shared between all the electrolyzers, so it is shown that the more electrolyzers installed, the fewer disturbances the system has because $\alpha$ tries to be in the nominal operating point.

Figs. 14-16 depict the results for the three small production electrolyzers. The performance of these electrolyzers can be considered correct because they operate between the constraints designed in this case study and they are also used more as they have better performance.

The last figure (Fig. 17) shows the production of hydrogen for all the 6 electrolyzers in this second scenario. The devices produce the maximum amount of hydrogen they can, so the design of the control algorithm can be considered efficient.

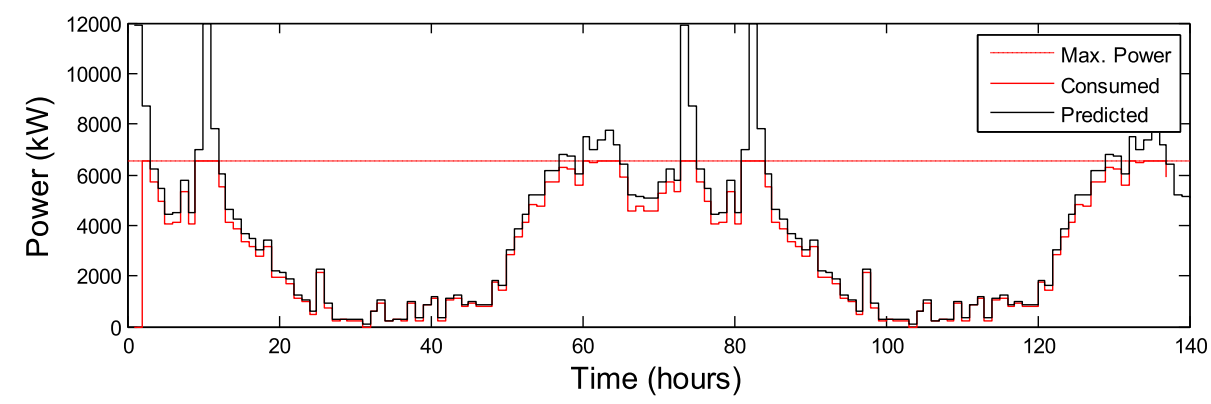

Fig. 10 - Power available and consumed second case study.

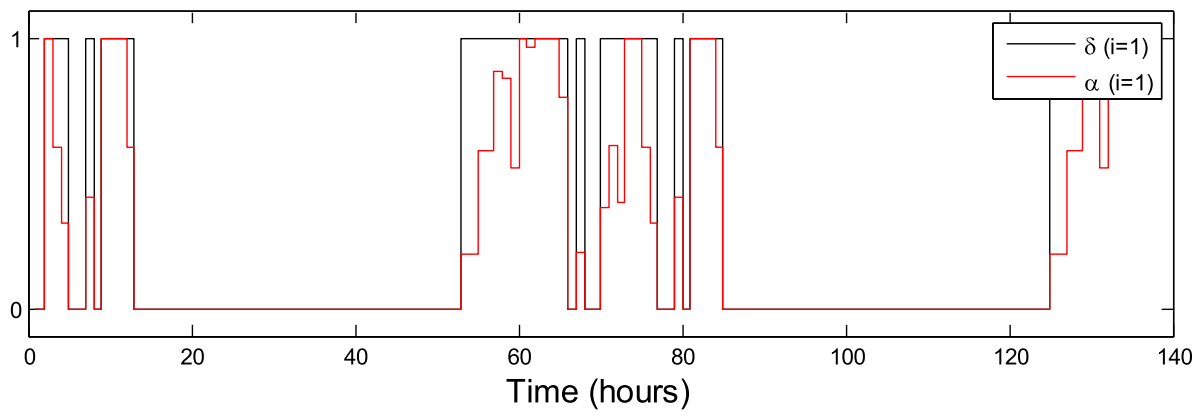

Fig. 11 - Performance of electrolyzer $n^{0} 1$ for the second case study. 


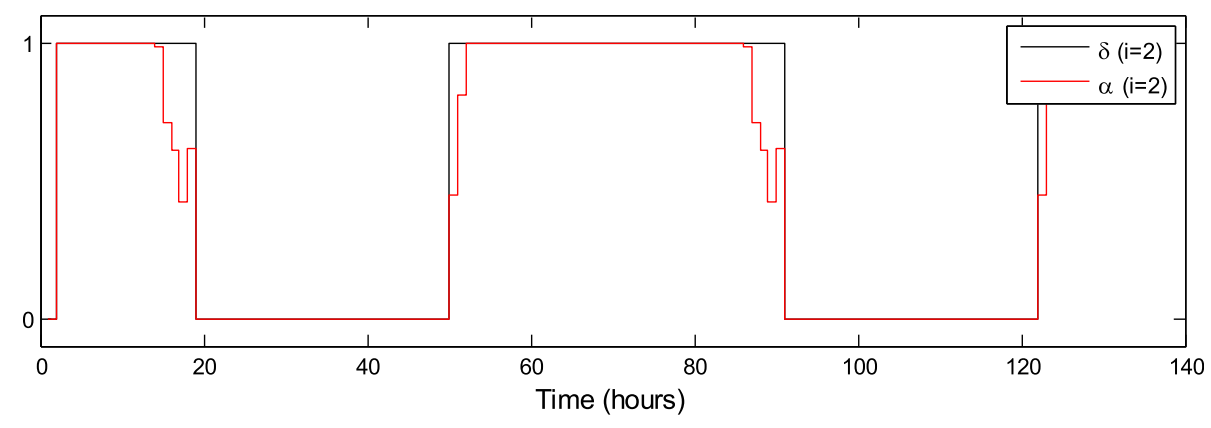

Fig. 12 - Performance of electrolyzer $n^{0} 2$ for the second case study.

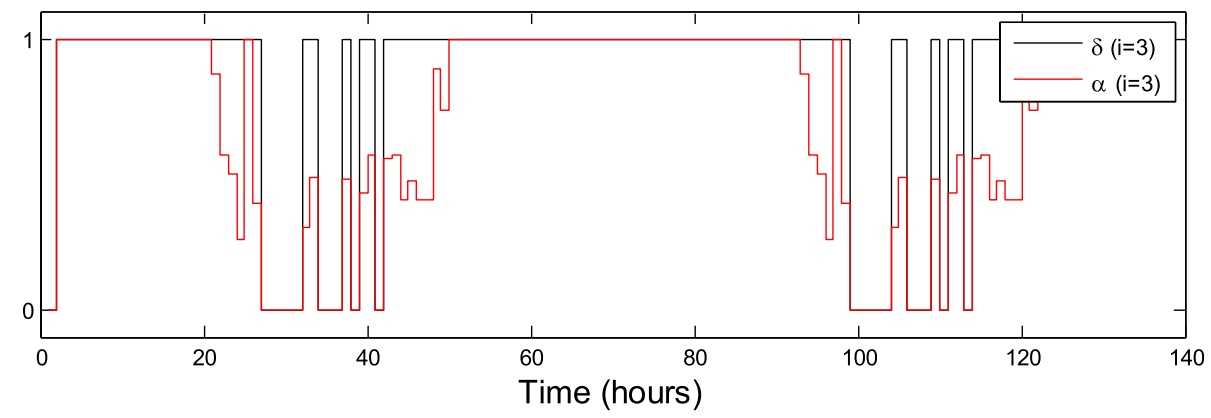

Fig. 13 - Performance of electrolyzer $n^{\circ} 3$ for the second case study.

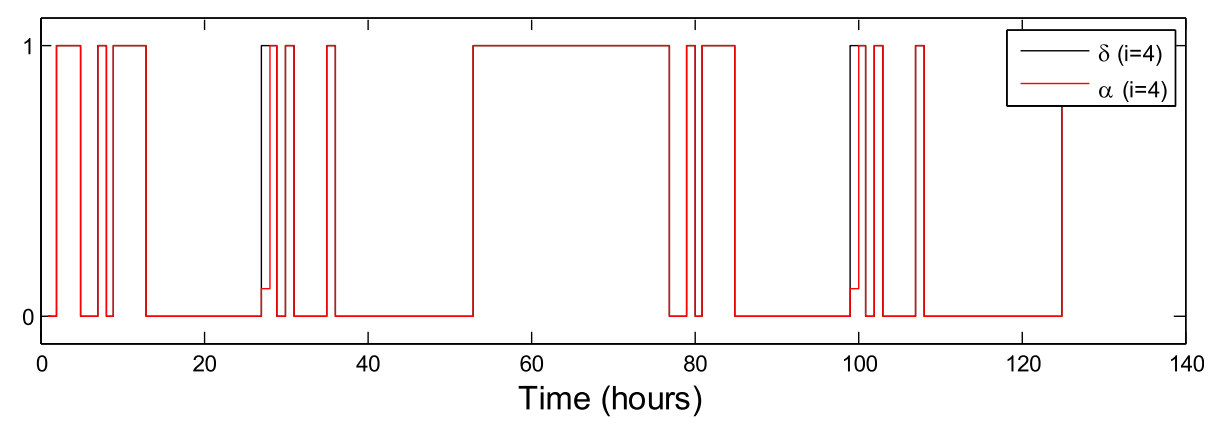

Fig. 14 - Performance of electrolyzer $n^{\circ} 4$ for the second case study.

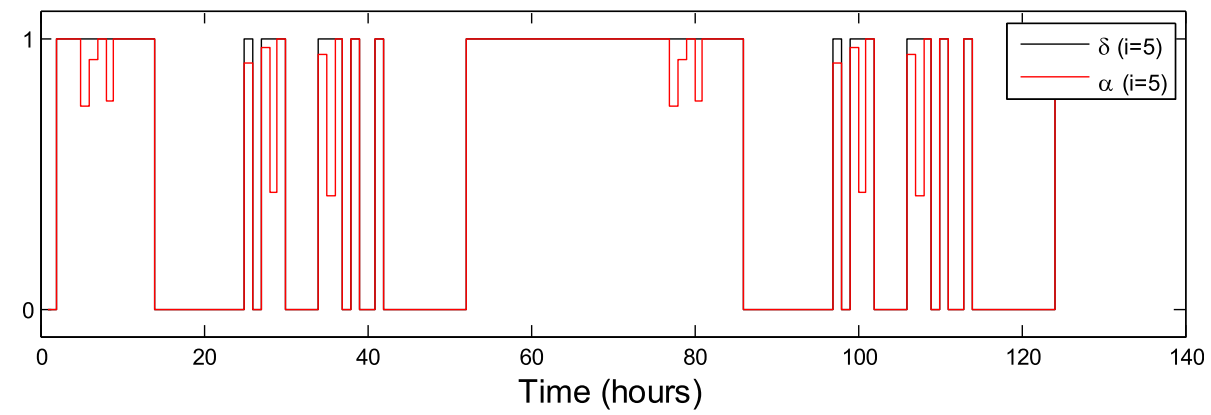

Fig. 15 - Performance of electrolyzer $n^{0} 5$ for the second case study. 


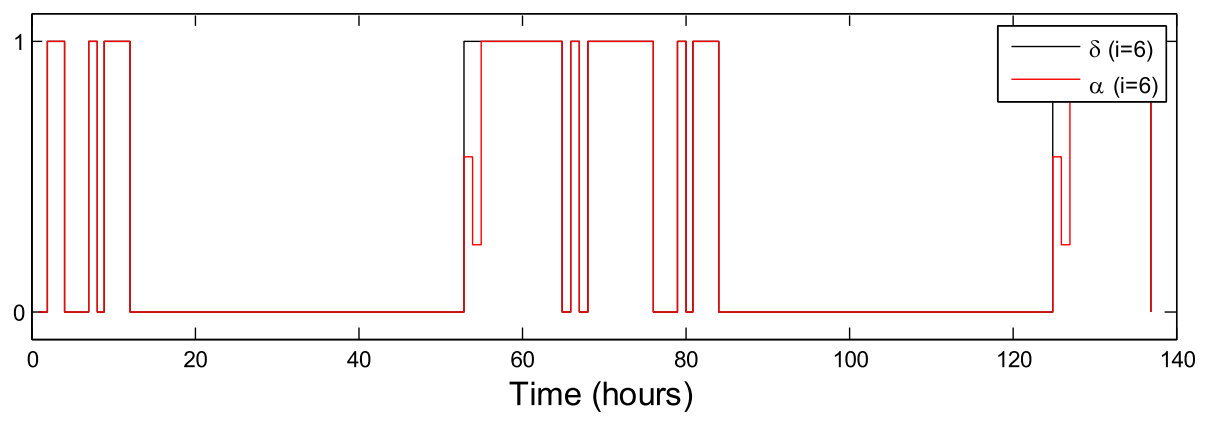

Fig. 16 - Performance of electrolyzer $n^{0} 6$ for the second case study.

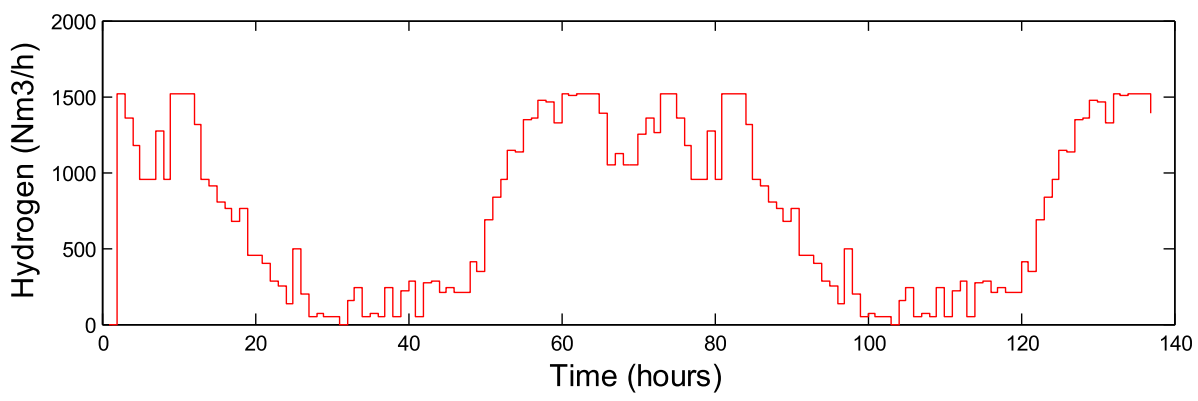

Fig. 17 - Hydrogen production for the second case study.

Table 1 - Performance indices and consumptions of the simulation in scenario 2.

\begin{tabular}{lll}
$\begin{array}{l}\text { Power available } \\
\text { (kW per day) }\end{array}$ & $\begin{array}{l}\text { Power consumed } \\
\text { (MWh per day) }\end{array}$ & $\begin{array}{l}\mathrm{H}_{2} \text { produced } \\
\left(\mathrm{Nm}^{3} / \mathrm{h}\right)\end{array}$ \\
27046.4 & $24249.8(88.6 \%)$ & 726.89 \\
Electrolyzer 1st & Electrolyzer 2nd & Electrolyzer 3rd \\
(ON/OFF cycles & (ON/OFF cycles & (ON/OFF cycles \\
$\quad$ per day) & per day) & per day) \\
2.91 & 0.85 & 2.91 \\
Electrolyzer 4th & Electrolyzer 5th & Electrolyzer 6th \\
(ON/OFF cycles & (ON/OFF cycles & (ON/OFF cycles \\
$\quad$ per day) & per day) & per day) \\
4.45 & 3.94 & 3.08 \\
\hline
\end{tabular}

Finally, to summarize this second scenario, some performance indices and consumptions are presented in Table 1 . These results confirm the high $\mathrm{H}_{2}$ mean production obtained from the available power and also the small number of ON/OFF cycles.

If compared to the ideal scenario of case 1, the real performance of scenario 2 can be considered very good. Note that, only when the available power was very low, did the controller not find a proper solution and the consumed power was under the desired value. This result is expected because of the constraints imposed on the minimum values of the operating points. In terms of power distribution between electrolyzers and switching ON/OFF of the equipment, both scenarios had expected results, confirming the good performance of the control strategy.

\section{Conclusions}

An Energy Management System algorithm based on a Model Predictive Control is proposed and tested to optimize and balance the $\mathrm{H}_{2}$ production for an offshore plant, which includes a set of electrolysis units, following the power provided by variable renewable energy sources (wind and waves). Using the Smart Grid concept, the characteristics of each electrolyzer are considered to improve the state-of-health of the units. The proposed approach has been validated using real data measured from a certain location in the north Atlantic Ocean, which is used to verify the correct operation of the platform with the designed controller.

The main conclusions of this study are the following:

1- The Mixed-Integer-Quadratic-Programming for the MPC allows the operating point of each electrolysis unit and its connections or disconnections to be regulated.

2- In the two cases studies, the error between the predicted and desired power consumed by each electrolyzer is minimized for all the devices along the prediction horizon.

3- The operation of the electrolysis set is maximized, since the discrete variables defining the connection/disconnection condition of the electrolysis is actioned along the prediction horizon, as much as possible.

4- The MPC control strategy ensures the continuity of the $\mathrm{H}_{2}$ production, since the energy consumed by the electrolysis is almost equal to the energy supplied from the wind and waves during the prediction horizon.

5- The electrolyzers' state of health is ensured, thanks to the minimization of the switching between the connection/ disconnection states.

\section{Acknowledgments}

This work was supported by MICINN 2014-54530-R and the European Commission (7th Framework Programme, grant 
agreement 288145, Ocean of Tomorrow Joint Call 2011). A. Serna thanks the financial support given by Junta de Castilla y León EDU/1083/2013. Part of this work was carried out financed by a mobility grant given by the University of Valladolid (Call 2015). Prof. Normey-Rico thanks CNPq-Brazil for financial support under projects 305785/2015-0 and 401126/ 2014-5. Dr. Yahyaoui is funded by a grant and a project (FAPES 0838/2015) from the Fundação de Amparo à Pesquisa e Inovação do Espirito Santo (FAPES), Brazil.

\section{Nomenclature}

n Number of electrolysis units

$\mathrm{N} \quad$ Prediction horizon

$\mathrm{N}_{\mathrm{u}} \quad$ Control horizon

$\mathrm{i} \quad$ Subscript of each electrolysis unit (from 1 to $\mathrm{n}$ )

$\delta_{\mathrm{i}}(\mathrm{k}) \quad$ Binary variable: ON/OFF electrolysis unit i at instant $\mathrm{k}$

$\widehat{\delta}_{\mathrm{i}}(\mathrm{k}) \quad$ Prediction of the binary variable: ON/OFF electrolysis unit $\mathrm{i}$ at instant $\mathrm{k}$

$\alpha_{\mathrm{i}}(\mathrm{k}) \quad$ Operating point of electrolysis unit $\mathrm{i}$ at instant $\mathrm{k}$

$\widehat{\alpha}_{i}(k) \quad$ Prediction of the operating point of electrolysis unit $i$ at instant $\mathrm{k}$

$\mathrm{z}_{\mathrm{i}}(\mathrm{k}) \quad$ Auxiliary variable of electrolysis unit $\mathrm{i}$ at instant $\mathrm{k}$

$\Delta z_{\mathrm{i}}(\mathrm{k}) \quad$ Increase of the auxiliary variable of electrolysis unit $\mathrm{i}$ at instant $\mathrm{k}$

$\widehat{\Delta z}_{i}(k) \quad$ Prediction of the increase of the auxiliary variable of electrolysis unit i at instant $\mathrm{k}$

$\mathrm{H}_{\mathrm{i}}(\mathrm{k}) \quad$ Hydrogen production of electrolysis unit $\mathrm{i}$ at instant $\mathrm{k}, \mathrm{Nm}^{3} / \mathrm{h}$

$a_{i} \quad$ Slope of power model of electrolysis unit $\mathrm{i}, \mathrm{kWh} / \mathrm{Nm}^{3}$

$b_{i} \quad$ Offset of power model of electrolysis unit $i, k W h /$

$\mathrm{Nm}^{3}$

$\underline{\alpha}_{i} \quad \bar{\alpha}_{i} \quad$ Minimum and maximum operating points of electrolysis unit i, \%

$\overline{\mathrm{H}}_{\mathrm{i}} \quad$ Maximum $\mathrm{H}_{2}$ production $\left(\mathrm{Nm}^{3} / \mathrm{h}\right.$ ) of electrolysis unit i

$P_{i}(k) \quad$ Power consumption of electrolysis unit i at instant k, $\mathrm{kW}$

$\overline{\mathrm{P}}_{\mathrm{i}} \quad$ Rated power of electrolysis unit $\mathrm{i}, \mathrm{kW}$

$\widehat{\mathrm{P}}_{\text {available }}(\mathrm{k})$ Prediction of power available to electrolysis at instant $\mathrm{k}, \mathrm{kW}$

$\mathrm{Q}_{\mathrm{H}} \quad$ Weighting of the error

$\mathrm{Q}_{\delta} \quad$ Weighting of the control variable

J Quadratic cost function, $\mathrm{Nm}^{3} / \mathrm{h}$

M Quadratic part of the cost function

1 Linear part of the cost function

A, B Constraints matrices

f Free response

G Gain of the manipulated variable

$\mathrm{X} \quad$ Decision vector

$\mathrm{k} \quad$ Time index

\section{REFERENCES}

[1] Larsson M, Mohseni F, Wallmark C, Grönkvist S, Alvfors P. Energy system analysis of the implications of hydrogen fuel cell vehicles in the Swedish road transport system. Int J Hydrogen Energy 2015;40(35):11722-9.

[2] Serna A, Tadeo F. Offshore hydrogen production from wave energy. Int J Hydrogen Energy 2014;39(3):1549-57.

[3] Sarrias-Mena R, Fernández-Ramírez LM, García-Vázquez CA, Jurado F. Electrolyzer models for hydrogen production from wind energy systems. Int J Hydrogen Energy 2015;40(7):2927-38.

[4] Andrews J, Shabani B. Re-envisioning the role of hydrogen in a sustainable energy economy. Int J Hydrogen Energy 2012;37(2):1184-203.

[5] Ribeiro AED, Arouca MC, Coelho DM. Electric energy generation from small-scale solar and wind power in Brazil: the influence of location, area and shape. Renew Energy 2016;85:554-63.

[6] Mostafaeipour A, Khayyami M, Sedaghat A, Mohammadi K, Shamshirband S, Sehati MA, et al. Evaluating the wind energy potential for hydrogen production: a case study. Int $J$ Hydrogen Energy 2016;41(15):6200-10.

[7] Boscaino V, Cipriani G, Curto D, Di Dio V, Franzitta V, Trapanese $\mathrm{M}$, et al. A small scale prototype of a wave energy conversion system for hydrogen production. In: IECON 2015-41st Annual Conference of the IEEE Industrial Electronics Society; 2015. Yokohama, Japan.

[8] Ghribi D, Khelifa A, Diaf S, Belhamel M. Study of hydrogen production system by using PV solar energy and PEM electrolyser in Algeria. Int J Hydrogen Energy 2013;38(20):8480-90.

[9] Serna A, Torrijos D, Tadeo F, Touati K. Evaluation of wave energy for a near-the-coast offshore desalination plant. In: World Congress on Desalination and Water Reuse (IDA); 2013. Tianjin, China.

[10] Bensmail S, Rekioua D, Azzi H. Study of hybrid photovoltaic/ fuel cell system for stand-alone applications. Int J Hydrogen Energy 2015;40(39):13820-6.

[11] Martínez M, Molina MG, Machado IR, Mercado PE, Watanabe EH. Modelling and simulation of wave energy hyperbaric converter (WEHC) for applications in distributed generation. Int J Hydrogen Energy 2012;37(19):14945-50.

[12] Joshi AS, Dincer I, Reddy BV. Solar energy production: a comparative performance assessment. Int J Hydrogen Energy 2011;36(17):11246-57.

[13] Valverde L, Pino FJ, Guerra J, Rosa F. Definition, analysis and experimental investigation of operation modes in hydrogenrenewable-based power plants incorporating hybrid energy storage. Energy Convers Manage 2016;113:290-311.

[14] Kalinci Y, Hepbasli A, Dincer I. Techno-economic analysis of a stand-alone hybrid renewable energy system with hydrogen production and storage options. Int J Hydrogen Energy 2015;40(24):7652-64.

[15] Serna A, Tadeo F. Offshore desalination using wave energy. Adv Mech Eng 2013;5:539857.

[16] Samrat NH, Ahmad N, Choudhury IA, Taha Z. An off-grid stand-alone wave energy supply system with maximum power extraction scheme for green energy utilization in Malaysian Island. Desalin Water Treat 2016;57(1):58-74.

[17] Alwi SRW, Rozali NEM, Abdul-Manan Z, Klemeš JJ. A process integration targeting method for hybrid power systems. Energy 2012;44(1):6-10.

[18] Serna A, Normey-Rico JE, Tadeo F. Mixed-integer-quadraticprogramming based predictive control for hydrogen production using renewable energy. In: 7th International Renewable Energy Congress (IREC); 2016. Hammamet, Tunisia.

[19] Stoutenburg ED, Jenkins N, Jacobson MZ. Power output variations of co-located offshore wind turbines and wave energy converters in California. Renew Energy 2010;35(12):2781-91. 
[20] Mo J, Dehoff RR, Peter WH, Toops TJ, Green JB, Zhang FY. Additive manufacturing of liquid/gas diffusion layers for low-cost and high-efficiency hydrogen production. Int J Hydrogen Energy 2016;41(4):3128-35.

[21] Ebbesen SD, Jensen SH, Hauch A, Mogensen MB. High temperature electrolysis in alkaline cells, solid proton conducting cells, and solid oxide cells. Chem Rev 2014;114(21):10697-734.

[22] Dumortier M, Marcano JS. Analytical evaluation of heat sources and electrical resistance of a cermet electrode for the production of hydrogen in a membrane reactor. Int $\mathrm{J}$ Hydrogen Energy 2015;40(8):3566-73.

[23] Petersen HN. Note on the targeted hydrogen quality produced from electrolyser units, Review of the Department of Energy Conversion and Storage. Technical University of Denmark; 2012.

[24] Rashid MM, Al Mesfer MK, Naseem H, Danish M. Hydrogen production by water electrolysis: a review of alkaline water electrolysis, PEM water electrolysis and high temperature water electrolysis. Int J Eng Adv Technol 2015;1(4):2249-8958.

[25] Morgan ER, Manwell JF, McGowan JG. Opportunities for economies of scale with alkaline electrolyzers. Int J Hydrogen Energy 2013;38(36):15903-9.

[26] Aranguren P, Astrain D, Santa María M, Rojo R. Computational study on a thermoelectric system used to dry out the hydrogen produced in an alkaline electrolyzer. Appl Therm Eng 2015;75:984-93.

[27] Serna A, Normey-Rico JE, Tadeo F. Model predictive control of hydrogen production by renewable energy. In: Renewable Energy Congress (IREC), 2015 6th International. Sousse. Tunisia: IEEE; 2015. p. 1-6.

[28] Camacho EF, Bordons C. Model predictive control. Springer; 2013.

[29] Gutiérrez-Martín F, Confente D, Guerra I. Management of variable electricity loads in wind-hydrogen systems: the case of a Spanish wind farm. Int J Hydrogen Energy 2010;35(14):7329-36.

[30] Torrico BC, Roca L, Normey-Rico JE, Guzman JL, Yebra L. Robust nonlinear predictive control applied to a solar collector field in a solar desalination plant. IEEE Trans Control Syst Technol 2010;18(6):1430-9.
[31] Scherer HF, Pasamontes M, Guzmán JL, Álvarez JD, Camponogara E, Normey-Rico JE. Efficient building energy management using distributed model predictive control. J Process Control 2014;24(6):740-9.

[32] H2Ocean-project.eu. 'H2ocean'. N.p., 2016. Web. 23 March 2016. Available at: http://www.h2ocean-project.eu/.

[33] Khalid M, Savkin AV. A model predictive control approach to the problem of wind power smoothing with controlled battery storage. Renew Energy 2010;35(7):1520-6.

[34] De Prada C, Sarabia D, Cristea S, Mazaeda R. Plant-wide control of a hybrid process. Int J Adapt Control 2008;22(2):124-41.

[35] Salazar J, Tadeo F, Valverde L. Predictive control of a renewable energy microgrid with operational cost optimization. In: Industrial Electronics Society, IECON 39th Annual Conference; 2013. Vienna, Austria.

[36] Wang M, Wang Z, Gong X, Guo Z. The intensification technologies to water electrolysis for hydrogen production a review. Renew Sustain Energy Rev 2014;29:573-88.

[37] Plucenio A, Pagano DJ, Bruciapaglia AH, Normey-Rico JE. A practical approach to predictive control for nonlinear processes. In: NOLCOS 2007. Proceedings of the NOLCOS 2007; 2007. Pretoria, South Africa.

[38] Bemporad A, Morari M. Control of systems integrating logic, dynamics, and constraints. Automatica 1999;35(3):407-27.

[39] da Costa Mendes PR, Normey-Rico JE, Bordons C. Economic energy management of a microgrid including electric vehicles. In: Innovative Smart Grid Technologies Conference Latinoamerica ISGTL; 2015. Montevideo, Uruguay.

[40] Dietrich K, Latorre JM, Olmos L, Ramos A. Demand response in an isolated system with high wind integration. Power Syst 2012;27(1):20-9.

[41] Appendini CM, Urbano-Latorre CP, Figueroa B, Dagua-Paz CJ, Torres-Freyermuth A, Salles P. Wave energy potential assessment in the Caribbean Low Level Jet using wave hindcast information. Appl Energy 2015;137:375-84.

[42] Borg M, Shires A, Collu M. Offshore floating vertical axis wind turbines, dynamics modelling state of the art. Part I: Aerodynamics. Renew Sust Energ Rev 2014;39:1214-25. 